\title{
O IMPACTO DA (IN)COMUNICAÇÃO PARA AS RELAÇÕES PERVERSAS NAS ORGANIZAÇÕES
}

\author{
The impact of (in) communication on perverses relations in organizations \\ El impacto de la (in)comunicación para las relaciones perversas en las \\ organizaciones
}

Fernanda Luz Moraes Mestrado em Comunicação Social pela PUCRS.

fernandamoraees@gmail.com

Renata Andreoni Diretora de Pós-Graduação Lato Sensu do Grupo Educacional IBCMED, Pós-Doutoranda em Comunicação na UFSM. andreoni.renata@gmail.com

Fernando Carara Lemos Mestrado com Comunicação Social pela PUCRS. ferclemospoa@gmail.com

\section{Resumo}

Ao compreendermos as relações enquanto práticas comunicacionais, entendemos a necessidade de revisitar as práticas de (in)comunicação nas organizações e seus impactos nas relações de trabalho. Este artigo parte do cenário de esgotamento do ser (HAN, 2017a e 2017b), que ganha relevância na sociedade de desempenho, flexível (SENNETT, 2006) e líquida (BAUMAN, 2006), tornando-se terreno fértil para relações perversas nos ambientes organizacionais, podendo resultar na prática do assédio moral organizacional (SILVA, 2016; SOBOLL, 2017). Recorremos ao Pensamento Complexo (MORIN, 2011; 2015) para sustentar a necessidade de refletirmos sobre uma dimensão cooperativa (LEMOS, 2019) e o desenvolvimento da potência vital da comunicação (ANDREONI, 2018), como possibilidade de (re)construir as relações no mundo do trabalho

Palavras-chave: Comunicação Organizacional. Relações Perversas. Potência Vital da Comunicação.

\section{Abstract}

As we understand the relationships as communication practices, it's necessary revisiting the (in)communication practices in organizations and their impacts on working relationships. This article starts from the scenario of the exhaustion of human being (HAN, 2017a and 2017b), 
which gains relevance in the performance society, flexible (SENNETT, 2006) and liquid (BAUMAN, 2006), becoming fertile ground for perverse relationships in organizational environments. and may result in the practice of organizational harassment (SILVA, 2016; SOBOLL, 2017). We use complex thinking (MORIN, 2011; 2015) to support the need to reflect on a cooperative dimension (LEMOS, 2019) and the development of the vital power of communication (ANDREONI, 2018) as a possibility to (re) build relationships in the world of labor.

Key words: Organizational communication. Perverse Relationships. Vital Power of Communication.

\section{Resumen}

Cuando entendemos las relaciones como prácticas de comunicación, entendemos la necesidad de revisar las prácticas de (in)comunicación en las organizaciones y sus impactos en las relaciones laborales. Este artículo parte del escenario del agotamiento del sujeto (HAN, 2017a y 2017b), el cual gana relevancia en la sociedad del desempeño, flexible (SENNETT, 2006) y líquido (BAUMAN, 2006), convirtiéndose en suelo fértil para las relaciones perversas en los entornos organizacionales y puede resultar en la práctica del acoso moral organizacional (SILVA, 2016; SOBOLL, 2017). Para el desarrollo del presente artículo, nos basamos en el pensamiento complejo (MORIN, 2011; 2015) para apoyar la necesidad de reflexionar sobre la dimensión cooperativa (LEMOS, 2019) y el desarrollo de la potencia vital de la comunicación (ANDREONI, 2018) como una posibilidad para (re)construir relaciones en el mundo laboral.

Palabras clave: Comunicación organizacional. Relaciones perversas. Potencia vital de la comunicación.

\section{CAMINHOS INICIAIS POSSÍVEIS}

As organizações que perfazem o mundo do trabalho são construídas cotidianamente por relações e, independentemente de suas atividades, serviços e/ou produtos, elas são (re)estruturadas por indivíduos e grupos em relação. Sob esta perspectiva, o fazer organizacional é antes de tudo um "fazer" comunicacional, isto é, um contínuo estar em relação, um movimento que não cessa, (des)articulando diferentes interesses e subjetividades. Nesta grande "arena" comunicacional do trabalho, habitualmente estruturada por níveis hierárquicos bem estratificados, podem emergir possíveis perversidades, culminando, por vezes, em configurações de assédios. Diante do exposto, propomos uma discussão teórica que nos permita compreender configurações de perversidades a partir do olhar comunicacional. Essa possibilidade se dá na tentativa de elucidar a centralidade da comunicação no mundo do trabalho, a partir do pensamento complexo (MORIN, 2011; 2015), para além de uma perspectiva funcionalista/instrumental. 
As perversidades são tecidas pela (in)comunicação, podendo gerar configurações como assédio moral organizacional e possíveis adoecimentos mentais e físicos nos trabalhadores, gerando impactos no dia a dia da organização, nas interações (re)tecidas, bem como na saúde de seus trabalhadores. Ao falarmos de (in)comunicação, estamos nos referindo ao sentido proposto por Wolton (2010, p. 62), ao enfatizar que: "Pensar a comunicação é pensar a incomunicação", destacando que ambas andam juntas. O autor chama a atenção para dimensões que são inerentes às relações, como diálogo e negociação, mas que acabam sendo desconsideradas na busca desenfreada por agilidade, pautada por uma ideologia tecnicista. Embora a comunicação seja tratada no senso comum, muitas vezes, como sinônimo de informação, simplificada ao sentido de transmissão, ela pressupõe sempre uma predisposição para sentir com, para viver a experiência da relação, sem reduzir-se à dinâmica do automatismo. Para que a comunicação se estabeleça é indispensável a abertura ao outro. De acordo com Wolton (2010, p. 62), é preciso conciliarmos “[...] dois movimentos contraditórios: o reconhecimento das identidades e a obrigação de construir a convivência cultural entre diferenças para evitar o comunitarismo".

A comunicação é, portanto, um encontro entre diferenças. Nesse sentido, propomos alguns tensionamentos que nos auxiliem a questionar compreensões simplistas, que conduzem à produtividade como o centro da organização e, por vezes, não consideram os indivíduos em sua totalidade. O privilégio de abordagens instrumentais, na emergência da (in)comunicação, pautadas pela intenção de controle e vigilância, pode ter como consequências a instauração de práticas comunicacionais dotadas de relações perversas (in)visíveis. Ao buscar traçar outras vias, propomos uma compreensão da comunicação sob uma perspectiva filosófica, mais especificamente, a partir da filosofia de Henri Bergson (1859-1941). A partir dessa abordagem, entendemos ser possível perceber e incorporar a comunicação muito além da perspectiva instrumental, mas enquanto uma potência vital no sistema organizacional.

\section{DA SOCIEDADE DO DESEMPENHO ÀS ORGANIZAÇÕES}

O panorama social lecionado por Han (2017a) revela a Sociedade do Desempenho, cujos sujeitos se mostram cansados e esgotados por si mesmos, em uma condição de autoexploração. O autor (HAN, 2017a) expõe que: “A sociedade do desempenho está totalmente dominada pelo verbo modal poder" (HAN, 2017b, p. 21).

Isso significa dizer que vivemos um movimento que vai além de uma sociedade disciplinar, como aquela referida por Foucault (2014), em que a vigilância e a punição atuam 
como dispositivos de poder na busca pelo corpo dócil. A abordagem foucaultiana é direcionada à disciplinarização dos corpos, na qual evidencia-se a produção de processos de assujeitamentos, ao mesmo tempo em que são gerados processos de resistências. Trata-se de uma rede microcapilar, na qual as relações de poder são permeadas, também, por resistências. O sujeito do desempenho trazido por Han (2017a; 2017b), por outro lado, se percebe como livre e não se sente submisso às ordens e explorações dos demais, atuando como um "empreendedor de si mesmo" (HAN, 2017b, p. 21). Por consequência, através da autoexploração, tem sua produtividade aumentada até que seu organismo ingresse em condições patológicas de esgotamento, tais como transtornos depressivos e burnout $^{l}$ (HAN, 2017a).

O que percebemos, como Han (2017b) ressalta, é um movimento no qual emerge a violência, que se manifesta através do sentimento de liberdade, e que tem como base a autoexploração.

A sociedade da positividade, que acredita ter-se libertado de todas as coações estranhas, se vê enredada em coações autodestrutivas [...] A gente faz violência a si mesmo e explora a si mesmo. Em lugar da violência causada por um fator externo, entra a violência autogerada, que é mais fatal do que aquela, pois a vítima dessa violência imagina ser alguém livre (HAN, 2017b, p. 102).

O contexto apresentado é o dos sujeitos que: "Estão por demais vivos, para morrer, e por demais mortos para viver" (HAN, 2017a, p. 109). Vivem sob uma necessidade de desempenho que os torna sujeitos cansados e, por consequência, doentes ${ }^{2}$. Sennett (2006) e Bauman (2007) reforçam a perversidade deste cenário. Para Sennett (2006), neste universo organizacional que prima por um modelo de gestão flexível, os indivíduos são incentivados a serem ágeis, o que fomenta um estado de ansiedade. Este ritmo acelerado contribui para uma desorganização do tempo, um dos motivos para superficialidade nas relações (SENNETT, 2006). Esta superficialidade pode ser reconhecida como um estado líquido, pela perspectiva de Bauman (2007), visto que "[...] a vida numa sociedade líquido-moderna não pode ficar parada" (BAUMAN, 2007, p. 9) e a intimidade ganha contornos superficiais. Em nossa percepção, visões que sustentam relações rasas fomentam o discurso do indivíduo individualista de Han (2017a, 2017b).

1 Burnout trata-se de um estado de esgotamento físico, emocional e mental (OIT, 2016).

2 Segundo relatório da Organização Mundial da Saúde, de 2017, a depressão caminha para ser a doença mais incapacitante do mundo, em 2020. 
Flexibilidade, agilidade e produção são termos que estão associados às Tecnologias de Informação e Comunicação (TICs) no mundo do trabalho e são pilares que sustentam a dinâmica empresarial neoliberal, conduzidas e fomentadas por uma dinâmica comunicacional instrumental. Em nosso entendimento, as tecnologias trazem para a comunicação organizacional um aspecto menos de interação entre pessoas e mais de regulação, na intenção de eliminar incertezas. "A noção comunicacional aparece definida como um mecanismo corretor, no sentido de sanear a instabilidade e proporcionar a clareza" (FAUSTO NETO, 2008, p. 44), status que reforça o papel instrumental da comunicação. Somos adeptos da perspectiva relacional da comunicação nos ambientes organizacionais, "como um processo de interação em que estão envolvidos interlocutores, mensagem, meio e contexto" (OLIVEIRA, 2009, p. 331). A organização é tida como um dos atores desta interação que se estabelece num espaço comum, onde se confrontam os interesses e expectativas de todos os envolvidos nesta relação (OLIVEIRA, 2009).

Faz-se importante lembrarmos que as organizações são sistemas vivos, constituídos por indivíduos e grupos portadores de desejos, pulsões e interesses díspares, (re)configurados por uma rede de (inter)subjetividades. Desconsiderar tais diferenças na busca de um consenso idealizado, em nome de uma produção ágil e automatizada, pode ser o terreno fértil para a imersão de possíveis perversidades. Diante do exposto, entendemos que, neste contexto, é preciso abordarmos essa discussão à luz da comunicação organizacional, na medida em que as relações no mundo do trabalho são (re)tecidas pela comunicação.

As organizações se auto-eco-organizam e se auto-eco-produzem (MORIN, 2011), assim como as relações em seu interior são complementares e antagônicas - um espaço de “[...] ambiguidade de luta, resistência, de colaboração, de antagonismo e de complementaridade necessária para a complexidade organizacional” (MORIN, 2011, p. 93). Esse sistema é complexo, na medida em que a complementariedade entre as partes é reconhecida e dotada de uma mistura de ordem e desordem natural (MORIN, 2011), já que “[...] o normal não é que as coisas permaneçam tais como são, pelo contrário, isso seria inquietante. Não há uma receita de equilíbrio” (MORIN, 2011, p. 89). Por vivenciarmos as ordens e desordens que emergem do/no sistema complexo (MORIN, 2011), é possível que, assim como exista a possibilidade de (re)construção de sentidos no ambiente organizacional, também haja sofrimento.

Trata-se do reflexo de uma relação de liberdade e, ao mesmo tempo, servidão. Uma relação que, como abordamos na compreensão de Han (2017a; 2017b), se manifesta por meio 
de uma falsa sensação de liberdade nos indivíduos, a ponto de fazer com que eles não percebam as relações de exploração que vivem, posto que eles são, simultaneamente, vítimas e exploradores (HAN, 2017a). Neste caso, não se trata de uma relação de opressão de um indivíduo e/ou grupo sobre outrem, mas de um contexto sócio-organizacional, no qual a autoexploração é incorporada por um imaginário marcado pelo "empreendedorismo de si”, regido pela falácia da autorresposabilização absoluta no alcance do nosso (in)sucesso, desconsiderando fatores contextuais - econômicos, sociais, geográficos, políticos etc.

$\mathrm{Na}$ contemporaneidade, nos deparamos em um cenário no qual as perversidades são deflagradas por um falso ideário de emancipação, em que tudo depende tão somente dos esforços individuais. Numa corrida desenfreada consigo, não há espaço/tempo para o outro. Da sociedade disciplinar para a sociedade do desempenho a perversidade é ressignificada, encontrando um terreno fértil para emergir e se proliferar, de forma mais implícita, porém, não menos pungente, se diluindo na tessitura das relações.

\begin{abstract}
A sociedade do trabalho e a sociedade do desempenho não são sociedades livres. Elas geram novas coerções. A dialética do senhor e escravo está, não em última instância, para aquela sociedade na qual cada um é livre e que seria capaz também de ter tempo livre para o lazer. Leva, ao contrário, a uma sociedade do trabalho, na qual o próprio senhor se transformou num escravo do trabalho. Nessa sociedade coercitiva, cada um carrega consigo seu campo de trabalho. A especificidade desse campo de trabalho é que somos ao mesmo tempo prisioneiro e vigia, vítima e agressor. Assim, acabamos explorando a nós mesmos. Com isso, a exploração é possível mesmo sem senhorio (HAN, 2017a, p. 46-47).
\end{abstract}

Sob essa perspectiva, os indivíduos só conseguem perceber o contexto em que estão inseridos quando encontram o eros, que arranca o sujeito de si mesmo e direciona-o para o outro. Isso significa livrar-se de uma condição que denomina como ensimesmamento, vez que: No inferno do igual, que vai igualando cada vez mais a sociedade atual, já não mais nos encontramos, portanto, com a experiência erótica. Essa experiência pressupõe a assimetria e exterioridade do outro (HAN, 2017b, p. 8).

Entendemos que a assimetria das relações entre os indivíduos (HAN, 2017a, 2017b) significa, também, perceber a naturalidade de sua (in)certeza - a ordem e a desordem (MORIN, 2011) - já que ela “[...] quebra nossas certezas artificiais e nos mostra os riscos de presente, os limites do saber [...] ela se opõe à tendência preguiçosa da mente que adere facilmente à convicção e tende a transformar a teoria em doutrina e, até mesmo, em dogma. (MORIN, 2015, p. 44). O que percebemos, no entanto, é uma tentativa das organizações em 
buscar, por vezes, possibilidades que rejeitam a assimetria das relações, através de práticas comunicacionais que, de certa forma, fazem com que as relações vivenciadas nas organizações adquiram uma carga simbólica em que a dimensão humana é negligenciada. Nos iludimos com a tentativa de negar os conflitos, como refere Roman (2009), ao invés de admiti-los como um acontecimento genuíno da auto-eco-organização (MORIN, 2011).

Neste contexto, há um terreno fértil às situações que promovem/estimulam a violência nas relações, muitas vezes, travestidas por discursos motivacionais e falsamente emancipatórios, com abordagens aparentemente inovadoras. Podem, portanto, apresentar um movimento que tem como objetivo a produtividade e que se vê oculto através de narrativas sedutoras e práticas que refletem na dignidade dos indivíduos, deixando as perversidades diluídas na tessitura das relações. Entretanto, faz-se importante considerarmos, também, outras configurações, como é o caso da prática do assédio moral organizacional, quando a violência se expressa com visibilidade ou de maneira velada, podendo acarretar sanções judiciais às organizações.

\section{ASSÉDIO MORAL ORGANIZACIONAL E AS RELAÇÕES PERVERSAS (IN)VISÍVEIS NAS ORGANIZAÇÕES}

O mundo do trabalho é cotidianamente (re)significado através de um movimento contínuo de tessitura das relações que nele emergem. Trata-se de meio de relação social (DEJOURS, 2004) que possibilita ao indivíduo constituir-se como um sujeito social.

Nessa relação, as incertezas e os dissensos são acontecimentos naturais quando analisados pelas lentes da complexidade (MORIN, 2011, 2015). Por outro lado, ao não reconhecer essa possibilidade - de o trabalho carregar as tensões inerentes das/nas relações as violências (in)visíveis podem ser geradas, na medida em que existe a exposição dos indivíduos a situações humilhantes e constrangedoras no ambiente de trabalho.

Quando, neste ambiente, as condutas se revelam de maneira sistemática, ou seja, ocorrem de forma contínua e não apenas em situações isoladas, estamos diante de uma prática denominada assédio moral (GOSDAL, 2017). Essa prática tem por objeto e/ou efeito a degradação das condições de trabalho e, também, consequências aos indivíduos, afetando sua dignidade, sua saúde física e/ou mental ou, então, podendo comprometer seu futuro profissional. Para Hirigoyen (2009), o assédio moral compreende toda e qualquer conduta abusiva que se manifesta, principalmente, por meio de comportamentos, palavras, atos e 
gestos que sejam danosos à personalidade, à dignidade e/ou à integridade física e/ou psíquica do indivíduo, podendo colocar em perigo seu emprego e/ou degradar o ambiente de trabalho.

Neste caso, a prática do assédio moral parte de um indivíduo específico e é designada a outro sujeito, de caráter individual, identificadas de maneira isolada e/ou em pequenos grupos (SILVA, 2016). Porém, na medida em que as condutas se manifestam sobre alvos coletivos em uma organização, com o intuito de aumentar a produtividade dos sujeitos naquele ambiente, a prática em questão é denominada assédio moral organizacional (SILVA, 2016). Tal acontecimento, portanto, compreende, na visão de Soboll (2017) situações continuadas de violência sutil ou explícita, utilizadas em políticas e nas práticas organizacionais e gerenciais ou ainda decorrente destas. No caso do assédio moral organizacional não se trata de afetar um sujeito específico, mas a configuração de uma dinâmica de violência que se dilui na cultura organizacional, em prol da produtividade.

Para a autora (SOBOLL, 2017), mesmo que o agressor possa ser identificável, ele não é personalizado, sendo que esta modalidade de assédio moral "[...] geralmente aparece com estratégias de gestão abusivas, as quais evidenciam a formulação de procedimentos e políticas organizacionais e não necessariamente a simples existência de um agressor personalizado" (SOBOLL, 2017, p. 15). Em nossa perspectiva, isso significa dizer que a prática do assédio moral organizacional está inserida, principalmente, na forma como o trabalho é organizado e tem como objetivo principal o aumento da produtividade. A violência se manifesta pelo (in)visível, sendo que as práticas são - na maioria das vezes - muito sutis e, em um primeiro momento ilegíveis, já que "[...] entre as trevas e a luz, há diversos tons de penumbra" (SILVA, 2016, p. 71).

É dizer que a prática está inserida, principalmente, em situações que, ao longo do tempo, podem causar sofrimento aos indivíduos envolvidos, em que: “Ao mesmo tempo, mesmo corroendo cotidianamente a motivação, segurança e autoestima dos trabalhadores, as tarefas continuam sendo realizadas" (FARAH, 2016, p. 47). Isso nos leva a questionar a necessidade de atenção das organizações para o reconhecimento da dimensão humana em detrimento à produtividade.

Como relações dotadas de potencialidades, do antagônico e complementar (MORIN, 2015), as perversidades podem emergir nas relações no mundo do trabalho - sutil ou explicitamente. Quando configuradas em assédio moral e/ou assédio moral organizacional, concentram-se no âmbito jurídico, no entanto, entendemos que a tessitura dessas relações se configuram pela comunicação. Tratam-se de práticas que abalam a dignidade dos indivíduos e 
que, em sua essência, revelam - em nossa compreensão - a existência de uma cultura dotada de um sentido de manipulação e assujeitamento, através dos movimentos comunicacionais que têm como consequência o sofrimento. Compreendemos que a (in)comunicação é a "rede invisível” pela qual as perversidades, e possíveis configurações de assédios, são (re)constituídas. Destarte, é emergente (re)pensar essas relações à luz da comunicação, na medida em que consideramos que há outras possibilidades de organização e vivência no [e para o] mundo do trabalho.

\section{COMUNICAÇÃO - POR UMA DIMENSÃO COOPERATIVA E UMA POTÊNCIA VITAL ÀS ORGANIZAÇÕES}

A comunicação, principalmente no contexto organizacional empresarial, é majoritariamente apreendida no sentido instrumental e operacional, como meio para a assertividade e a reprodutibilidade. Entretanto, como já abordamos, precisamos ampliar esta visão, assumindo que as organizações são espaços de relação e, portanto, de complexidade. Premissas como alteridade, contingência, diálogo, conflito, negociação, entre outras dimensões humanas, precisam ganhar centralidade no pensar e fazer comunicacional. Nesse sentido, propomos abordar a comunicação sob uma perspectiva filosófica, mais especificamente, a partir de uma breve aproximação com o pensamento filosófico de Henri Bergson.

A filosofia bergsoniana nos possibilita compreender as condições da realidade como possibilidades indeterminadas, na medida em que propõe a compreensão da vida pelo movimento sucessivo do tempo, constituído por um fluxo contínuo, uma realidade metafísica [temporal] que coexiste com a física [espacial]. Trata-se de compreendermos a vida pela concomitância de duas dimensões da realidade - virtual e atual. A metafísica bergsoniana se estabelece pelas suas especificidades, na medida em que encontra sua imanência na experiência, na "relação com". Essa abordagem de pensamento nos parece, portanto, pertinente para pensarmos a comunicação e as diferentes formas que desenvolvemos de experienciar.

O pensamento bergsoniano versa sobre a dualidade duração e espaço, constituindo, assim, a unidade da vida. De acordo com o filósofo, somos seres de inteligência, voltados a “[...] objetivos a serem alcançados, isto é, pontos de repouso" (BERGSON, 2005, p. 324), mas, também, somos seres de intuição, de movimento contínuo. Em termos de condições, somos capazes de estabelecer relações de entendimento, ao buscarmos, por meio da 
linguagem, "[...] estabelecer comunicação com vista a uma cooperação” (BERGSON, 2006, p. 90). Nossas condições, movidas pela inteligência prática, nos permitem contar com a previsibilidade, “[...] esclarecer nossa conduta, preparar nossa ação sobre as coisas, prever [...] os acontecimentos favoráveis ou desfavoráveis que possam ocorrer" (BERGSON, 2005, p. 32). É, portanto, pelas nossas condições, promovidas pela inteligência, que podemos nos (re)organizar enquanto estruturas sociais/organizacionais, buscando atingir determinados fins, baseados em relações de entendimento. No entanto, como possibilidades, transformamos e criamos premissas que não emergem de um processo indutivo e/ou analítico, mas de uma experiência estética. Sentimos e, portanto, (re)agimos. Essa (re)ação pode passar por um intervalo de hesitação, no qual suspendemos a realização automatizada/prática, e somos capazes de indeterminar o determinado. Além de cooperação, a comunicação é transformação, uma emoção criadora que afeta o sujeito pela alteridade da percepção, constituindo um intervalo entre, possibilitando um hiato de indeterminação que, preenchido pela memória, transforma nossas dimensões de possíveis condições em um multiverso virtual, enquanto realidade em potência, de possibilidades a serem atualizadas.

Diante do exposto, propomos compreender a comunicação enquanto um processo vital, pelo qual se dá as condições de produção dos indivíduos e das sociedades, que se realizam pela (inter)ação do Eu/Outro [no Mundo], da tensão do tempo no espaço. Trata-se da articulação de dimensões físicas e metafísicas, que se unificam pela experiência. A ação pode ser prática, voltada ao pragmatismo, às necessidades vitais ou, então, criadora, que inventa a vida, as individualidades, as sociedades, gerando novos sentidos, possibilitando a transformação e a (re)configuração das estruturas. Nesse sentido, a comunicação se relaciona diretamente à moral, que por questões práticas costuma operar de forma fechada, mas que pode se abrir, enquanto uma moral de aspiração, na medida em que somos impulsionados por uma emoção criadora, que emerge de uma comunicação simpática [sentir com], vivida pela experiência, realizando-se na liberdade de criar, pois a vida está sempre vindo a ser. Trata-se de uma continuidade e transformação ininterrupta, possibilitada por uma existência temporal, que dura (que nunca deixa ser, embora deixe de ser útil, mas que permanece no tempo, enquanto uma memória cosmológica). É pelo tempo, portanto, que a imprevisibilidade se faz e nos permite a liberdade do Ser em relação, ou melhor, em comunicação Eu/Outro.

O pensamento filosófico pode parecer distante da realidade orgânica e funcional das organizações. A linguagem, por vezes, rebuscada e metafórica da Filosofia pode ser outro fator de distanciamento. Entretanto pode se configurar como uma alternativa aos estudos 
focados nas premissas do "como fazer" e "como aplicar", direcionados ao controle e a eficácia. No momento em que acolhemos as incertezas, a investida filosófica pode ser um caminho profícuo à comunicação, na construção de outros (re)conhecimentos e possibilidades às abordagens comunicacionais no contexto das organizações.

Se compreendermos a comunicação enquanto uma potência vital, grávida de vida, de pulsões, perceberemos que é por ela que (re)encontramos a força para a transformação e a ressignificação das estruturas postas. O (re)pensar e o (re)fazer comunicacional é um esforço que devemos manter aceso e contínuo se desejarmos que as perversidades se desfaçam diante da falácia do controle e se abra para a difícil, mas extremamente transformadora e criadora, relação com o Outro.

Em nosso entendimento, para que seja possível desenvolver um ambiente propício para o desenvolvimento da potência vital da comunicação, vislumbramos a quinta dimensão da comunicação organizacional, a dimensão cooperativa (LEMOS, 2019). Esta dimensão propõe articular as quatro dimensões da comunicação organizacional (KUNSCH, 2016): administrativa, estratégica, cultural e humana. Para Lemos (2019), enquanto as dimensões comunicacionais forem tratadas de forma isolada nos ambientes organizacionais, os indivíduos continuarão a enfrentar dificuldades para se relacionar com a alteridade.

Para construção da proposta desta nova dimensão, o autor recorre à Sennett (2006), quando reforça que a cooperação é fruto de habilidades dialógicas - ações como ouvir com atenção, ações com tato, encontro de convergência e gestão de pontos de vista discordantes. O que percebemos em nossas vivências profissionais e pesquisas acadêmicas é uma prevalência de habilidades sociais superficiais, que visam o aumento de produtividade: "a comunicação interpessoal restringe-se a uma boa articulação de ideias em reuniões de negócios e, também, em coquetéis, para o fortalecimento de networking" (LEMOS, 2019, p. 58).

É preciso atentarmos para o desenvolvimento de competências que promovam uma nova consciência comunicacional nas organizações, para além dos discursos motivacionais e de tentativas dispersas de engajamento. A era do controle, ou das narrativas retóricas que não se sustentam nas práticas cotidianas, precisa dar passagem para que novas relações se estabeleçam. É necessário investirmos em uma compressão e atuação complexa, que nos capacite a lidar com pressupostos éticos bem sedimentados, baseados em princípios como: respeito, alteridade e argumentação. Entendemos que a via para a ressignificação do mundo do trabalho encontra-se numa ação interdisciplinar, tecida pela comunicação. 


\section{CONSIDERAÇÕES PROVISÓRIAS}

Ao propormos esta discussão teórica, buscamos evidenciar a comunicação enquanto um processo/fenômeno complexo, pelo qual as organizações se (re)configuram e atuam no mundo. Independentemente de seu fim, dos serviços e/ou produtos oferecidos, as organizações se (re)estruturam por/em relações. Sob essa perspectiva destacamos a centralidade da comunicação, para além dos seus propósitos funcionais, (re)pensá-la enquanto dimensão ontológica da organização. A partir do momento em que reconhecemos a comunicação enquanto uma potência vital da organização é possível problematizarmos estruturas e dinâmicas hegemônicas. Entendemos que o olhar filosófico para a comunicação nos permite um afastamento do tecnicismo utilitário, nos possibilitando questionar determinadas práticas e seus possíveis impactos, assim como vislumbrar outras possibilidades, para além das que estão postas.

Conforme abordado, as perversidades (in)visíveis permeiam as relações organizacionais, gerando configurações de assédios que impactam a vida dos trabalhadores. Compreendemos que problematizar este cenário, com vistas a transformá-lo, tecer alternativas e gerar mudança, pressupõe (re)pensar a forma como nos relacionamos e como buscamos gerar sentido e impactar o outro. O cenário de perversidades que está posto no contexto organizacional, em prol da produtividade desejada, vem gerando um efeito contrário, adoecimentos, afastamentos, desengajamento, exaustão. Nesse sentido, entendemos que a Comunicação, enquanto área de conhecimento, precisa se fazer presente nesta discussão, sob uma perspectiva crítica e propositiva, delineando tessituras que nos permitam vislumbram outros caminhos para (re)estabelecermos relações no mundo do trabalho. Aproximar esta discussão teórica de dados empíricos, dos impactos que estão sendo gerados na realidade contemporânea, é um possível futuro direcionamento a ser estabelecido.

\section{REFERÊNCIAS}

BAUMAN, Zygmunt. Vida líquida. Tradução de C. A. Medeiros. Rio de Janeiro: Jorge Zahar Ed., 2007.

BERGSON, Henri. O pensamento e o movente. São Paulo: Martins Fontes, 2006.

BERGSON, Henri. A evolução criadora. São Paulo: Martins Fontes, 2005.

FAUSTO NETO, Antonio. Comunicação das organizações: da vigilância aos pontos de fuga. In: OLIVEIRA, Ivone de L., SOARES, Ana T. N. Interfaces e tendências da comunicação no contexto das organizações. São Caetano do Sul, SP: Difusão, 2008. p. 39-63. 
FOUCAULT, Michel. Vigiar e punir: nascimento da prisão. Tradução de Raquel Ramalhete. 42 ed. Petrópolis, RJ: Vozes, 2014.

GOSDAL, Thereza Cristina. O entendimento do assédio moral e organizacional na justiça do trabalho. In: SOBOLL, Lis Andrea Pereira (Org). Intervenções em assédio moral e organizacional. - São Paulo: LTr, 2017.

HAN, Byung-Chul. Sociedade do cansaço. Trad. Enio Paulo Giachini. $2^{\text {a }}$ ed. Ampliada - Petrópolis, RJ: Vozes, 2017a.

HAN, Byung-Chul. Agonia do eros. Trad. Enio Paulo Giachini. Petrópolis, RJ: Vozes, 2017b.

HIRIGOYEN, Marie-France. Assédio moral: a violência perversa do cotidiano. Tradução de Maria Helena Kuhner. 11 ${ }^{\mathrm{a}}$ ed. Rio de Janeiro: Bertrand Brasil, 2009.

KUNSCH, Margarida Maria Krohling. A comunicação nas organizações: dos fluxos lineares às dimensões humana e estratégica. In: KUNSCH, M. M. K. (Org.) Comunicação organizacional estratégica: aportes conceituais e aplicados. São Paulo: Summus, 2016.

LEMOS, Fernando Carara. Dimensões possíveis para uma ressignificação da comunicação interna no contexto organizacional. 2019. 116 p. Dissertação (Mestrado em Comunicação Social) Faculdade de Comunicação Social, Pontifícia Universidade Católica do RS, Porto Alegre, 2019.

MORIN, Edgar. Introdução ao pensamento complexo. Tradução Eliane Lisboa. 4 ed. Porto Alegre: Sulina, 2011.

MORIN, Edgar. Ensinar a viver: manifesto para mudar a educação. Tradução: Edgar de Assis Carvalo e Mariza Perassi. Porto Alegre: editora Sulina, 2015.

OLIVEIRA, Ivone de Lourdes. Espaços dialógicos e relacionais nas organizações e sua natureza éticopolítica. In: KUNSCH, Margarida M. Krohling Kunsch (Org.). Comunicação organizacional: linguagem, gestão e perspectiva. São Paulo: Saraiva, 2009. p. 321-322.

ROMAN, Arthur. Organizações: um universo de bem-ditos, mal-ditos e nãoditos. In: KUNSCH, Margarida M. K. (Org). Comunicação organizacional: linguagem, gestão e perspectivas. São Paulo: Saraiva, 2009.

SENNETT, Richard. A corrosão do caráter: consequências pessoais do trabalho no novo capitalismo. Tradução de Marcos Santarrita. 11. ed. Rio de Janeiro: Record, 2006.

SENNETT, Richard. Juntos: Os rituais, os prazeres e a política da cooperação. Tradução de Clóvis Marques. Rio de Janeiro: Record, 2012.

SILVA, Jorge Luiz de Oliveira da. A síndrome de bournout como consequência do assédio moral no ambiente de trabalho. In: FARAH, Bruno Leal (Org). Assédio moral e organizacional: novas modulações do sofrimento psíquico nas empresas contemporâneas. São Paulo: LTr, 2016.

SOBOLL, Lis Andréa. Assédio moral e organizacional na perspectiva psicossocial: critérios obrigatórios e complementares. In: SOBOLL, Lis Andrea Pereira (Org). Intervenções em assédio moral e organizacional. São Paulo: LTr, 2017

WOLTON, Dominique. Informar não é comunicar. Tradução Juremir Machado da Silva. Porto Alegre: Sulina, 2011. 
WORLD HEALTH ORGANIZATION. Depression and Other Common Mental Disorders: Global Health Estimates. Geneva, [2017]. Disponível em: http://apps.who.int/iris/bitstream/10665/254610/1/WHO-MSD-MER-2017.2-eng.pdf?ua=1. Acesso em: 20 out. 2018.

Original recebido em: 19 de novembro de 2019

Aceito para publicação em: 30 de junho de 2020

Fernanda Luz Moraes

Mestrado em Comunicação Social pelo Programa de Pós-Graduação em Comunicação Social (PPGCom) da Pontifícia Universidade Católica do Rio Grande do Sul (PUCRS). Bacharela em Ciências Jurídicas e Sociais (PUCRS) e Bacharela em Relações Públicas (PUCRS). E-mail: fernandamoraees@gmail.com.

Renata Andreoni

Diretora de Pós-Graduação Lato Sensu do Grupo Educacional IBCMED, Pós-Doutoranda em Comunicação na UFSM. Doutora em Comunicação Social (PUCRS/Sorbonne-Paris IV). Mestra em Comunicação Social (PUCRS). Especialista em Gestão Cultural, Patrimonial e Turismo Sustentável (Fundación Ortega y Gasset - Buenos Aires/ARG). Licenciada em História (IPA). E-mail: andreoni.renata@gmail.com.

Fernando Carara Lemos

Mestre em Comunicação (PUCRS). MBA em gestão Empresarial (IBGEN). Relações Públicas (UNISINOS). E-mail: ferclemospoa@gmail.com

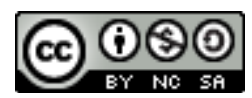

Esta obra está licenciada com uma Licença

Creative Commons Atribuição-NãoComercial-CompartilhaIgual 4.0 Internacional 